\title{
Isocapnic hyperventilation provides early extubation after sevoflurane anaesthesia for major ENT surgery: a clinical feasibility study
}

Katarina Hallén, Pether Jildenstål, Ola Stenqvist, Sven-Erik Ricksten, Sophie Lindgren Dept of Anaesthesiology and Intensive Care Medicine, Institute of Clinical Sciences, The Sahlgrenska Academy, (6) Gothenburg University, Sweden. Email: katarina.hallen@vgregion.se

\section{BACKGROUND}

Isocapnic hyperventilation (IHV) is a method that shortens time to extubation after inhalation anaesthesia by increasing airway $\mathrm{CO}_{2}$ during hyperventilation (HV). $(1,2)$ In a pilot study on patients undergoing long-duration sevoflurane anaesthesia for major ear-nose-throat (ENT) surgery, we evaluated the feasibility of an alternative technique of IHV. $(3,4)$

\section{METHODS}

Fifteen adult patients weighing $76 \pm 12 \mathrm{~kg}$ were included. After end of surgery mechanical $\mathrm{HV}$ was started and $\mathrm{CO}_{2}$ delivered $\left(\mathrm{DCO}_{2}\right)$ to the inspiratory limb of a closed standard breathing circuit. (Figure 1) $\mathrm{DCO}_{2}$ was dosed according to gender and weight, based on previous experimental studies. $(3,4)$ Time to extubation and eye-opening was recorded. Inspired $\left(\mathrm{FICO}_{2}\right)$ and expired $(\mathrm{FETCO})_{2} \mathrm{CO}_{2}$ and arterial $\mathrm{CO}_{2}$ levels were monitored during IHV. (Figure 2) Cognition was tested preoperatively and at 20, 40 and $60 \mathrm{~min}$ after arrival in the PACU.

\section{RESULTS}

$\mathrm{A} \mathrm{DCO}_{2}$ of $285 \pm 45 \mathrm{ml} / \mathrm{min}$ was necessary to achieve isocapnia during $\mathrm{HV}$. The corresponding $\mathrm{FICO}_{2}$-level was $3.0 \pm 0.3 \%$.

Time from turning off the vaporizer $(1.3 \pm 0.1 \mathrm{MAC})$ to extubation $(0.2 \pm 0.1$ $\mathrm{MAC}$ ) was $11.3 \pm 1.8 \mathrm{~min}$ (range $8-14 \mathrm{~min}$ ) after 342 $\pm 131 \mathrm{~min}$ (range 206-676 $\mathrm{min}$ ) of anaesthesia. $\mathrm{PaCO}_{2}$ and $\mathrm{FETCO}_{2}$, remained at normal levels during and after IHV. In $85 \%$ of patients postoperative cognition returned to preoperative values within 60 minutes. (Table 1, 2)

\section{CONCLUSION}

- The patients were safely extubated shortly after discontinuing long-term sevoflurane anaesthesia.

- Perioperatively, we did not find any adverse effects on arterial blood gases or postoperative cognition.

- Use of standard anaesthesia monitoring is sufficient for easy administration of $\mathrm{CO}_{2}$ during hyperventilation and

- $\mathrm{FICO}_{2}$ and $\mathrm{FETCO}_{2}$ values can be used to fine tune $\mathrm{DCO}_{2}$ during isocapnic hyperventilation

- This alternative method for IHV can potentially be used to decrease emergence time from inhalation anaesthesia.

Figure 1

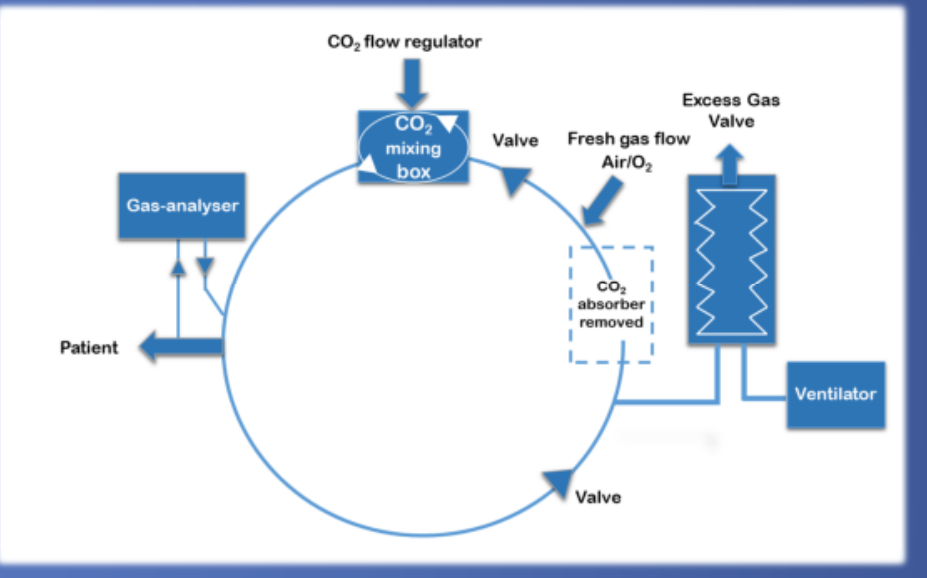

Figure 2

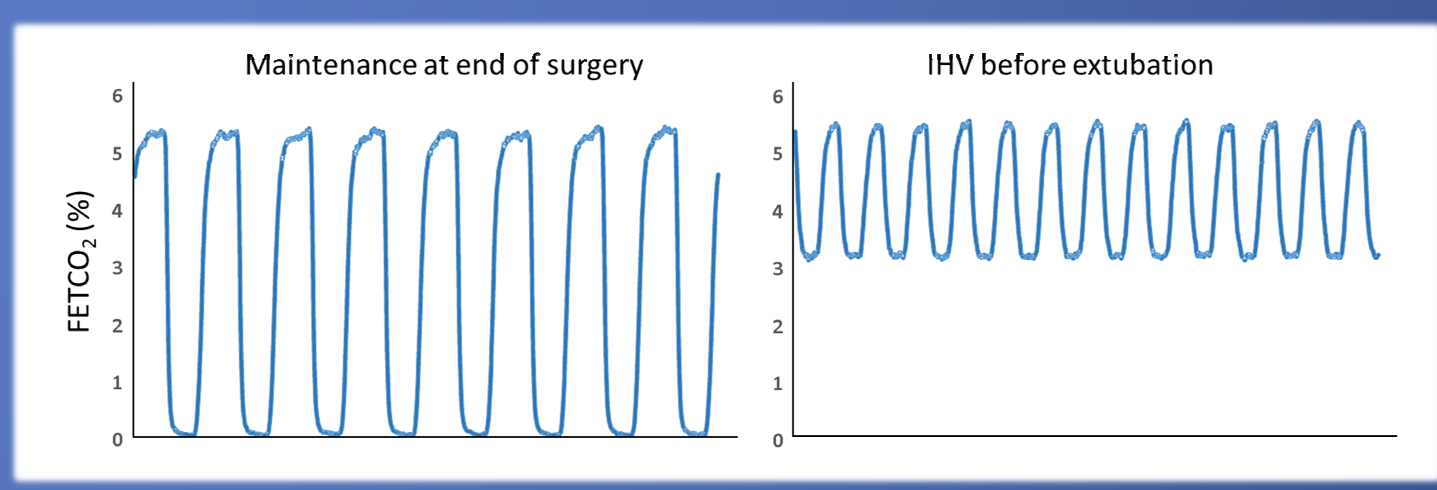

Table 1. Time intervals from end of sevoflurane administration to extubation, eye-opening and discharge from the operating room in a feasibility study of an alternative method for isocapnic hyperventilation after major ENT surgery. $N=15$, Mean \pm SD

Time to extubation $(\mathrm{min})$

Time to open eyes $(\mathrm{min})$

Time to discharge from operation $(\mathrm{min})$

Table 2. Postoperative physiological, pain and recovery variables at arrival and 20, 40 and $60 \mathrm{~min}$ after arrival in the post anaesthesia care unit (PACU).

\begin{tabular}{|c|c|c|c|c|}
\hline & $\begin{array}{l}\text { At arrival in } \\
\text { PACU }\end{array}$ & $\mathrm{T}_{20} \mathrm{~min}$ & $\mathrm{~T}_{40} \mathrm{~min}$ & $\mathrm{~T}_{60} \mathrm{~min}$ \\
\hline \multicolumn{5}{|l|}{ Gas exchange } \\
\hline $\mathrm{ETCO}_{2}(\%)$ & $5.0 \pm 0.8$ & $4.9 \pm 0.9$ & $5.1 \pm 0.5$ & $4.9 \pm 0.7$ \\
\hline $\mathrm{PaCO}_{2}(\mathrm{kPa})$ & $5.5 \pm 0.6$ & $5.3 \pm 0.7$ & $5.8 \pm 1.7$ & $5.2 \pm 0.4$ \\
\hline $\mathrm{SaO}_{2}(\%)$ & $97 \pm 2$ & $97 \pm 1$ & $97 \pm 1$ & $97 \pm 3$ \\
\hline $\mathrm{PaO}_{2}(\mathrm{kPa})$ & $13.3 \pm 3.1$ & $15.0 \pm 3.1$ & $14.9 \pm 4.4$ & $14.8 \pm 3.0$ \\
\hline P/F ratio & $44 \pm 17$ & $51 \pm 12$ & $53 \pm 18$ & $52 \pm 14$ \\
\hline \multicolumn{5}{|c|}{ PONV and nociception (\% of patients) } \\
\hline Nausea and vomiting 0 & 80 & 80 & 80 & 80 \\
\hline PQRS N1 (Pain) & NA & 80 & 86 & 86 \\
\hline PQRS N2 (PONV) & NA & 80 & 80 & 80 \\
\hline \multicolumn{5}{|c|}{ Cognition (\% of patients recovered) } \\
\hline Sedation score 0-1 & 53 & 100 & 93 & 100 \\
\hline PQRS C1-5 & NA & 31 & 77 & 85 \\
\hline
\end{tabular}

